\title{
Study Analysis of IoT in FMCG Smart Tags and their Significance in Counterfeit Prevention
}

\author{
Kedri Janardhana ${ }^{1}$, Razmah Mahaboobjan ${ }^{2}$, M. Vijayaragavan ${ }^{3}$, K. Vinoth ${ }^{4}$, \\ N.Kanagavalli ${ }^{5}$ \\ \{janardhankedri@dei.ac.in ${ }^{1}$, razmah.eee@sairamit.edu.in², mrvijay.ragavan@gmail.com³ \\ kvinoth@veltech.edu.in ${ }^{4}$,kvalli.818@gmail.com ${ }^{5}$ \}
}

${ }^{1}$ Assistant Professor (Senior Grade), Department of Electrical Engineering, Faculty of Engineering, Dayalbagh Educational Institute (Deemed to be University), Agra, India

${ }^{2}$ Assistant Professor, Sri Sai Ram Institute of Technology, Chennai, India

${ }^{3}$ Assistant Professor, Department of Electrical and Electronics Engineering, Mailam Engineering College, Mailam, India

${ }^{4}$ Assistant Professor, Department of Electrical and Electronics Engineering, Vel Tech Rangarajan Dr.Sagunthala R\&D Institute of Science and Technology, Chennai, India

${ }^{5}$ Assistant Professor, Department of Computer Science and Engineering, Rajalakshmi Institute of Technology, Chennai, India

\begin{abstract}
Current study portrays a novel method for counterfeit prevention and brand security in the FMCG business. The introduced approach consolidates Internet of Things, Cloud, and Mobile advancements with the utilization of specially crafted savvy labels (smart tags) applied to each product to give track and follow capacities. The smart labels join QR code with extra data printed with an imperceptible photochromatic ink. The labels are enacted by spotlight on cell phones during the checking. Prior to checking, clients are provoked to choose the setting of the products (available, sold, and consumed) to give extra data about each product container as it travels through the inventory network. Consumer family types reveals essential information on family types and roles in selecting the product for purchasing. The statistical analysis of family type is 84.7 and 15.2 percentage (out of 354 members) in nuclear and joint family respectively. Awareness percentage on smart tags is $49.15,32.17$ and 18.07 percentage in consumer awareness, unaware and may be respectively. Analysis of fake products identification on smart tags is $53.67,27.96$ and 18.36 percentage in consumer identification, unidentified, and may be respectively. Counterfeit information on products identification on smart tags is $97.74,2.259$ percentage in counterfeit information obtained by consumer is higher than not obtained consumers. Analysis of benefit percentage on products is 94.63, 5.37 percentage in benefit percentage is higher than non- obtained consumers. Likeliness of IoT - Smart Tags on products is $76.28,23.72$ percentage (out of 354 members) in interested percentage is higher than not interested consumers.
\end{abstract}

Keywords: Digital Transformation, Human Sensor Network; Smart Tags; Brand Protection, Counterfeit Prevention, Fast Moving Consumer Goods.

\section{Introduction}

Fast Consumer Goods (FMCG) there is a complete issue of non-brand goods and products [1]. The product business is not a special case and the counterfeit product is a real problem for 
manufacturers and customers [2,3]. Fraudulent product influences the shape and profit of the manufacturer, however it can also harm consumers. The overall product market analysis shows that the market share of counterfeit in the product industry falls in the range of $0.2 \%$ to $1 \%$, while a few tests have increased to $4-5 \%$ [4,5]. Many emotional tests come from China where a fraction of the total counterfeit product imported from Europe has been tested to be about $20 \%$ and in some cases very high, while product consumption is rising which makes China a fast-growing product market, ahead of the US and Russia [3,6,7 ].

The most popular way to create a product is to print a fake logo that takes a different brand name and invisible changes in the brand name and logo of friends to deceive the buyers of the products. Often, forgers use valid names derived from more expensive products and see them in less expensive products with similar jars. Finally, in some cases the drink inside the bottles is a counterfeit product, representing a major health concern, and [7]. This is a real issue in Montenegro, as a remnant of Southeast Europe, which was one of the formal promotions of this work. Figure 1 shows cases of fraudulent Montenegro products sold in the Western Balkans and Eastern Europe. In these cases, words that have the same appearance as the first one are used. The most curious model is a five-liter jug of product that has never been sold for a five-liter bulk.

Food security is an important and increasingly fundamental problem due to population growth and the current approach to agribusiness creation [8,9]. The design of the Internet of Things (IoT) is another unique benefit of farming and networking in general. Combined with other fine data (IT) patterns, it will play an important role in the advanced transformation of agriculture and food production through brilliant associations of compatible materials that can be detected, detected and remotely controlled [10], [11], [12]. The basic development of IoT applications in transmission and distribution is common in precision farming, food tracking and subsequent, welfare and quality management, food preparation and integration, and food consumer [8]. Food identification frameworks, often restricted by applicable laws, are often achieved through cultural frameworks, within an independent organization or part of a food production network using important developments and paper routes [13].

The arrangement furnishes a portable application that collaborates with purchasers such that each time clients check a QR code remarkably recognizing an item moment (for example product bottle), they give a report on the status and area of that specific container. In this manner, each jug is independently followed and followed all through the store network and these data updates can be utilized to recognize whether there is an expected fake issue with that specific jug.

\section{Research Methods}

A semi-structured qualitative preliminary study that focused on consumer's perceptions of smart labelling. The study involved 354 members who were generally familiar with smart labelling - IoT. The results indicate that the respondents could see the benefits of the technology. 


\section{DataCollection}

A quantitative approach was taken through a large-scale data collection via an online survey research. This research was able to call upon members whom met the predetermined demographic criteria of the survey, in this case, household grocery decision makers between the ages of 18 and 65 .

\begin{tabular}{|l|l|}
\hline S.No & Attributes \\
\hline 1 & Name \\
\hline 2 & Age \\
\hline 3 & Sex \\
\hline 4 & Educational qualification \\
\hline 5 & Marital status \\
\hline 6 & Residential location \\
\hline 7 & Occupation \\
\hline 8 & Family type \\
\hline 9 & Household shopping \\
\hline 10 & Do you aware of smart ags \\
\hline 11 & can you identify the fake products \\
\hline 12 & Reliability of smart tags \\
\hline 13 & Is it important to gather information regarding counterfeit? \\
\hline 14 & Do you think that our community will benefit from IoT based Smart tags \\
\hline 15 & $\begin{array}{l}\text { Is it important to educate consumer about counterfeit and how to report one? } \\
\end{array}$ \\
\hline 16 & Do you think consumer would like the smart tags \\
\hline
\end{tabular}

Weka 3.9.8. tool has implemented for the analysis and the below methods have implemented in this research work.

\section{Results And Discussion}

Study results indicates the significance of IoT based smart tags. Quality analysis of various parameter including consumer family type, awareness on smart tags, Identification of fake products, importance of counterfeit information, benefits of smart tag, likeliness of IoT smart tags

\section{Qualitative analysis:}

Analysis of consumer family

Consumer family types reveals essential information on family types and roles in selecting the product for purchasing. The statistical analysis of family type is 84.7 and 15.2 percentage (out of 354 members) in nuclear and joint family respectively (Figure $1 \&$ Table $1)$.

Table 1. Analysis of consumer family

\begin{tabular}{|l|l|l|l|}
\hline S.No & $\begin{array}{l}\text { Family } \\
\text { Type }\end{array}$ & weight & Percentage \\
\hline 1 & Nuclear & 300 & 84.7 \\
\hline
\end{tabular}




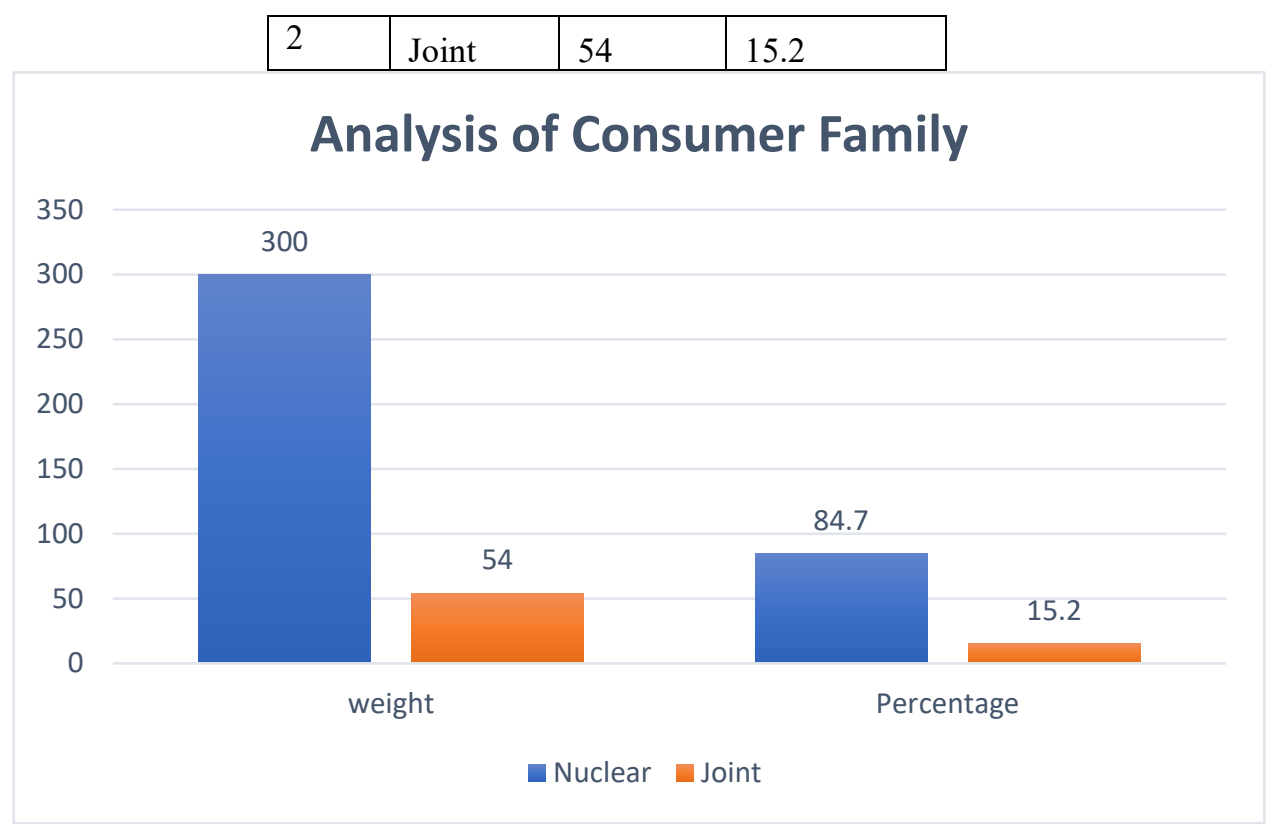

Figure 1. Analysis of consumer family

\section{Awareness on smart tags}

IoT based Smart tags predict the essential data information on selecting the product for purchasing. Awareness on smart tags by consumer is needed for betterment of IoT. The statistical analysis of awareness on smart tags is $49.15,32.17$ and 18.07 percentage (out of 354 members) in consumer awareness, unaware and may be respectively(Figure $2 \&$ Table 2).

\begin{tabular}{|c|c|c|c|}
\hline No ${ }^{S}$. & Label & ge Weighta & ge \\
\hline 1 & $e$ Awar & 174 & 49.15 \\
\hline 2 & are ${ }^{\text {Unaw }}$ & 116 & 32.7 \\
\hline 3 & be May & 64 & 18.07 \\
\hline
\end{tabular}




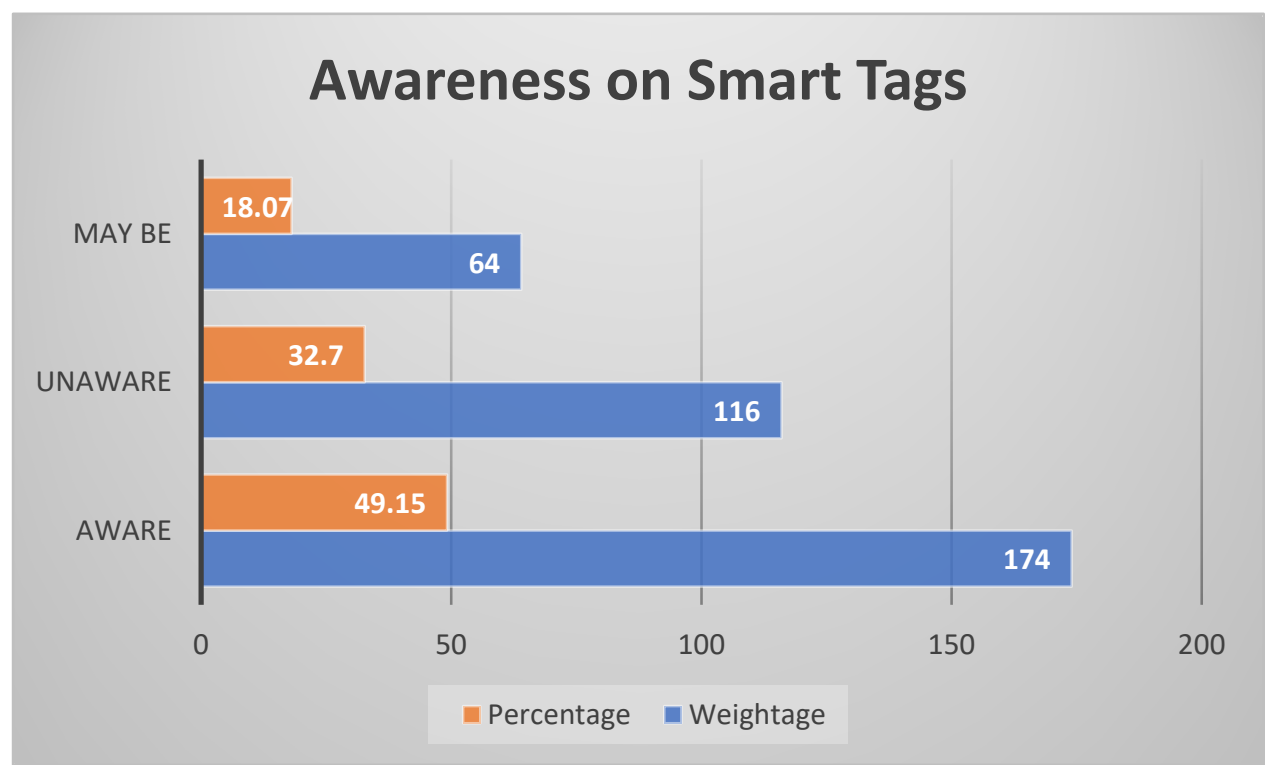

Figure 2. Awareness on smart tags

\section{Identification of fake products}

IoT based Smart tags predicting the fake products for choosing the product for purchasing. Identification of fake products by consumer is needed for betterment of IoT. The statistical analysis of fake products identification on smart tags is 53.67, 27.96 and 18.36 percentage (out of 354 members) in consumer identification, unidentified, and may be respectively(Figure $3 \&$ Table 3 ).

Table 3. Identification of fake products

\begin{tabular}{|c|c|c|}
\hline Parameter & Count & Percentage \\
\hline Identified & 190 & 53.67 \\
\hline Unidentified & 99 & 27.96 \\
\hline May be & 65 & 18.36 \\
\hline
\end{tabular}




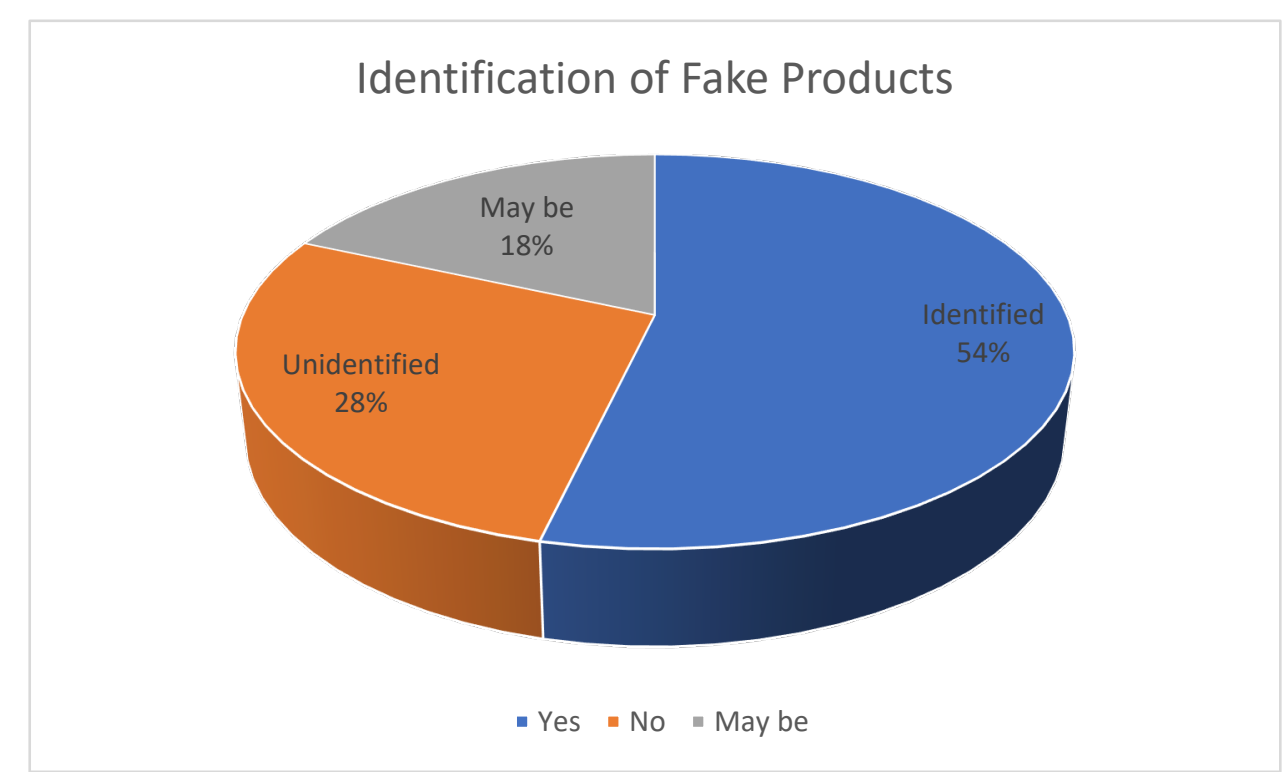

Figure 3. Identification of fake products

\section{Importance of Counterfeit information}

Counterfeit information should be known be the consumer in general. Information on counterfeit products enable consumer for choosing good products. The statistical analysis of Counterfeit information on products identification on smart tags is 97.74, 2.259 percentage (out of 354 members) in counterfeit information obtained by consumer is higher than not obtained consumers(Figure $4 \&$ Table 4 ).

Table 4. Importance of Counterfeit information
\begin{tabular}{|l|l|l|}
\hline & Total & Percentage \\
\hline Obtained & 346 & 97.74 \\
\hline Not obtained & 8 & 2.259 \\
\hline
\end{tabular}




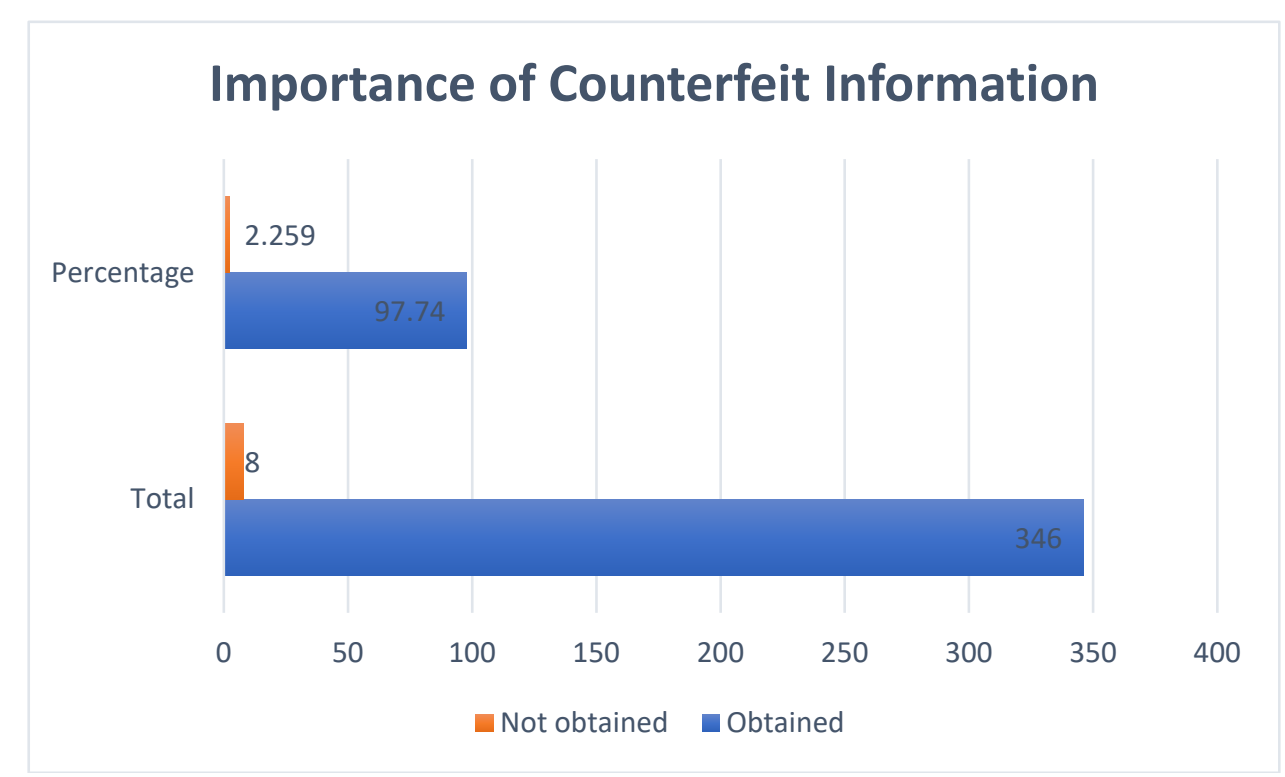

Figure 4. Importance of Counterfeit information

\section{IoT Smart tags - Benefit percentage}

Smart tags benefit percentage is very essential for fast moving consumer good. Information on benefit percentage enable consumer for aware more on choosing good products. The statistical analysis of benefit percentage on products is $94.63,5.37$ percentage (out of 354 members) in benefit percentage is higher than non- obtained consumers(Figure $5 \&$ Table 5).

Table 5. IoT Smart tags - Benefit percentage

\begin{tabular}{|l|l|l|}
\hline & Total & Percentage \\
\hline Benefited & 335 & 94.63 \\
\hline Not benefited & 19 & 5.37 \\
\hline
\end{tabular}




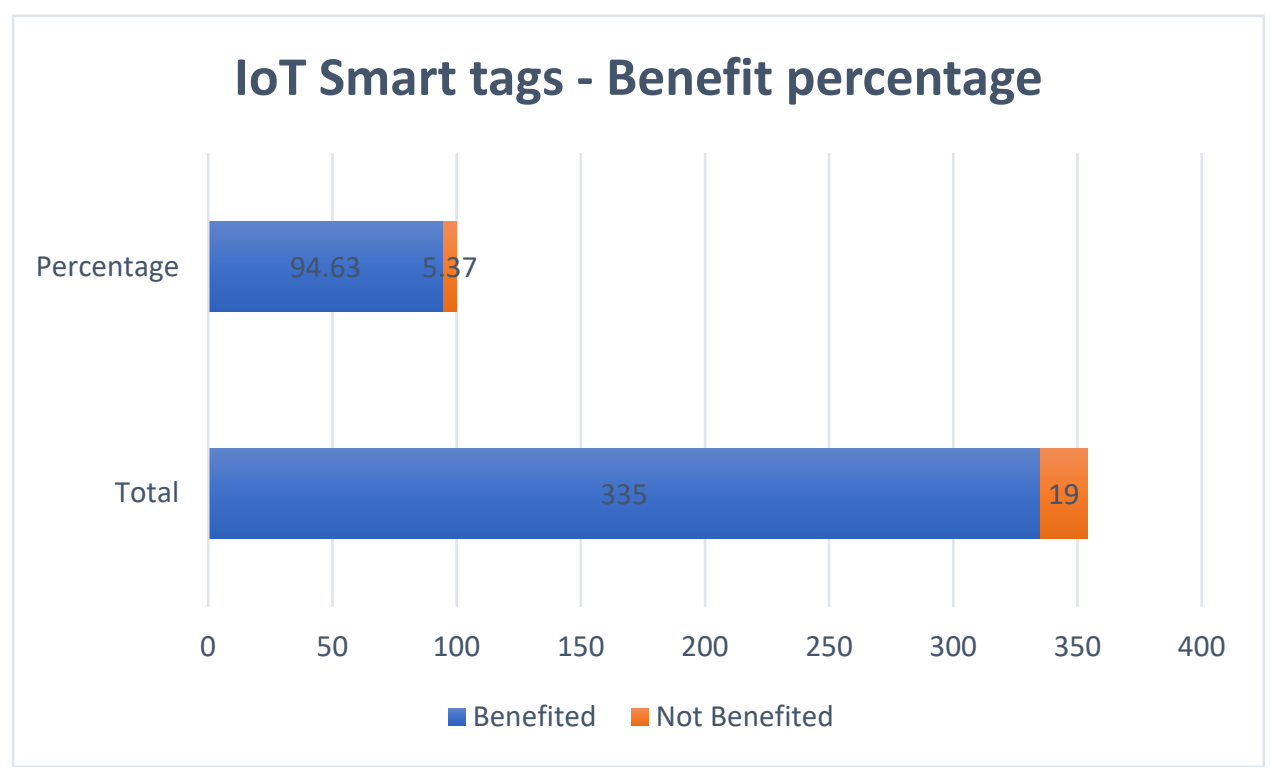

Figure 5. IoT Smart tags - Benefit percentage

\section{Likeliness of IoT - Smart Tags}

Smart tags likeliness percentage is one of essential criteria for fast moving consumer good. Information on Likeliness of IoT - Smart Tags enable consumer for aware more on choosing good products. The statistical analysis of Likeliness of IoT - Smart Tags on products is $76.28,23.72$ percentage (out of 354 members) in interested percentage is higher than not interested consumers(Figure 6\& Table 6).

Table 6. Likeliness of IoT - Smart Tags

\begin{tabular}{|l|l|l|}
\hline & Total & Percentage \\
\hline Interested & 270 & 76.28 \\
\hline Not Interested & 84 & 23.72 \\
\hline
\end{tabular}




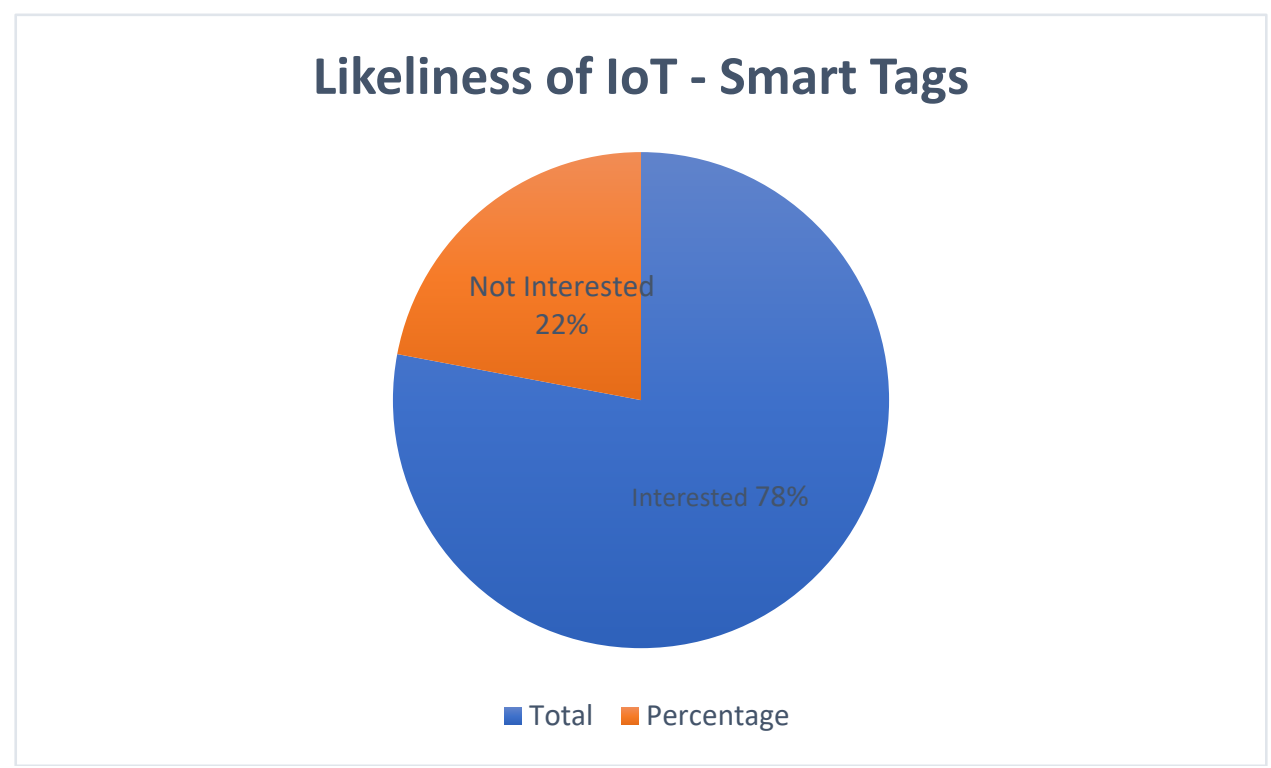

Figure 6. Likeliness of IoT - Smart Tags

The need to combat counterfeiting in the global manufacturing network is widely recognized and various alternatives and approaches have been proposed to address this issue $[1,2]$. These processes apply to the product business $[2,14]$. There are arrangements based on the IOT BASED SMART TAGS label that may be below the lower stage, as IOT BASED SMART TAGS users are less available $[15,16]$. Then again, preparations based on ink are highly adaptable to the point of execution [17,18], but they are easy to imitate [14]. A few experts suggest the use of preparations based on glittering materials [19] or unusual examples [20], but there is a need for more help with these methods. Product tracking and tracking arrangements based on the use of single product bottle numbers using the OCR method can be considered, but the disadvantage is that the accuracy of the reading and use of different text styles and numerical programs for different product types [21]. Frameworks of object identification and anti-fraud based on the use of QR codes are generally accepted by consumers and often require a camera with a camera [22,23]. The naming of Blockchain similarly finds its use in the production network of application managers [24,25], and its new record recording could allow for the selection of cloud-based frameworks soon.

This paper outlines the implementation of a pilot project that uses a variety of methods to create a product validation framework and false arguments in the product business. This method is powered by IoT, distributed by archiving and investigating information, mobile applications, and randomly labelled based on unique QR codes. The use of awesome labels creates a parallel space, where everything that happens is visible, using the new techniques provided by Horizon 2020 TagItSmart! project [26,27]. If it is not a very common problem, note that the standard standard tags distinguish the type of object that currently does not provide data for the same item [28]. It is worth noting that the GS1 Digital Link Standard has been redesigned in TagItSmart! making and donating marks the use of QR code, (IoT based Smart Tags), closed field communication (NFC), and Bluetooth to transmit information to their customers [29]. The common idea is to provide limited web-enabled provision to 
improve consumer purchasing experience, strengthen product reliability, and improve store network availability and efficiency.

Surprisingly the use of smart labels is that the general protests of the massive market that are not considered part of the IoT biological system can be provided by sharp labels that allow them to radically change their individual status by relying on environmental changes [30, 31]. Another important part of this method used to detect human-enabled detection is cell phone access everywhere with their cameras [32].

\section{Conclusion}

This data is utilized by the uniquely designed heuristic to help clients and manufacturer recognize issues with singular cases of the item. The framework was carried out as a pilot project that was executed during a time of a half year. End clients showed an incredible interest in the likelihood to carry out such a framework, customers preferred the cooperation with the item utilizing the portable mobile application and smart labels, while product manufacturer communicated their advantage in the arrangement. Other than fake that influences benefit, the advantages of such frameworks incorporate improved brand security and diminished danger of health hazards.

\section{References}

[1] Brandel, M. (2003). Smart tags, high costs. ComputerWorld (Dec. 15, 2003).

[2] Hoy, M. B. (2013). Near Field Communication: Getting in Touch with Mobile Users. Medical reference services quarterly, 32(3), 351-357.

[3] Lee, Y., Kozar, K. A., \& Larsen, K. R. (2003). The technology acceptance model: Past, present, and future. Communications of the Association for Information Systems, 12(1), 50.

[4] Morgan, R. M., \& Hunt, S. D. (1994). The commitment-trust theory of relationship marketing. the journal of marketing, 20-38.

[5] Östman, H. (2013, 11 April 2013 ). Grocery industry operations are facing a real paradigm shift. IOT BASED SMART TAGSAreana.Retrievedfromhttp://www.IoT based smart tagsarena.com/2013/4/11/grocery---industry--- operations---are---facing---a---real---paradigm--shift.aspx

[6] Pikkarainen, T., Pikkarainen, K., Karjaluoto, H., \& Pahnila, S. (2004). Consumer acceptance of online banking: an extension of the technology acceptance model. Internet research, 14(3), 224-235.

[7] J.M. Soon et al. Developing anti-counterfeiting measures: the role of smart packaging. (2019)

[8] Y.G. Kim et al. Consumer acceptance of a quick response (QR) code for the food traceability system: Application of an extended technology acceptance model (TAM). (2016)

[9] L. Li. Technology designed to combat fakes in the global supply chain (2013)

[10] H. Scholten Defining and analysing traceability systems in food supply chains" a chapter in "Advances in food traceability techniques and technologies" (2016)

[11] G. Baldini, I.N. Fovino, R. Satta, A. Tsois, E. Checchi, "Survey of techniques for the fight against counterfeit goods. N.C.K. Yiu. An NFC-Enabled Anticounterfeiting System for Wine Industry. (2014)

[12] A. Chéron. La protection et la contrefaçon de vins en France et à l'étranger" [The protection and counterfeiting of wine in France and abroad]Le Journal du Net(28 June 2013)

[13] B. Lecat. Fraud and counterfeit wines in France: an overview and perspectives. Br. Food J.(2017) 
[14] R. Pender. Counterfeit Wine - Its Impact on the Business of Wine. (March 2010)

[15] E. Przyswa, Counterfeiting In The Wines And Spirits Market: Key Issues And Presentation Of Anti-Counterfeiting...

[16] E. Przyswa, "Protecting Your Wine: Stop counterfeiters from selling cheap imitations of your premium brand", article in..

[17] Harald Sundmaeker"Internet of Food and Farm 2020", Chapter in "Digitising the Industry"(2016).

[18] W. SarniFrom Dirt to Data, The second green revolution and the Internet of Trhings"Deloitte Rev.(2016)

[19] C.N. Verdrouw. Virtualizaion of food supply chains with the internet of things. J. Food Eng.(2015)

[20] S. Li. The internet of things: a survey. (2015)

[21] Z. Pang. Value-centric design of the internet-of-things solution for food supply chain: Value creation, sensor portfolio and information fusion. (2015)

[22] A. Rida et al.Development and Implementation of Novel UHF Paper-Based IOT BASED SMART TAGS Designs for Anti-counterfeiting and Security Applications

[23] B. Yan et al.Application of IOT BASED SMART TAGS and internet of things in monitoring and anti-counterfeiting for products.

[24] S.C.Z. Chen et al.Anti-counterfeit authentication system of printed information based on a logic signing technique

[25] Davis, F. D. (1989). Perceived usefulness, perceived ease of use, and user acceptance of information technology. MIS quarterly, 319-340.

[26] Davis, F. D., Bagozzi, R. P., \& Warshaw, P. R. (1989). User acceptance of computer technology: a comparison of two theoretical models. Management science, 35(8), 982-1003.

[27] Dawes, J. G. (2008). Do data characteristics change according to the number of scale points used? An experiment using 5 point, 7 point and 10 point scales. International journal of market research, 51(1).

[28] Fornell, C., \& Larcker, D. F. (1981). Structural equation models with unobservable variables and measurement error: Algebra and statistics. Journal of marketing research, 382-388.

[29] Fry, R. (2013). A Rising Share of Young $\begin{array}{clll}\text { Adults Live } & \text { in Their Home. }\end{array}$ http://www.pewresearch.org: Pew Research Center. Retrieved from http://www.pewsocialtrends.org/files/2013/07/SDT---millennials---living---with---parents--07---2013.pdf

[30] Furrer, O., \& Sudharshan, D. (2001). Internet marketing research: opportunities and problems.

[31] Qualitative Market Research: An International Journal, 4(3), 123-129.

[32] Fusaro, R. A. (2004). None of our business? 